\title{
EXPERIÊNCIAS ESTÉTICAS NA EDUCAÇÃO INFANTIL A PARTIR DE PRÁTICAS PEDAGÓGICAS DESENHADAS PELA ARTE - A CAMINHADA DESTA PESQUISA
}

\author{
Andréia Haudt da Silva ${ }^{\mathrm{i}}$ \\ Maristani Polidori Zamperetti ${ }^{\text {ii }}$
}

\begin{abstract}
Resumo: Este artigo trata das contribuições da pesquisa: Experiências estéticas na educação infantil - práticas pedagógicas desenhadas pela arte. A pesquisa foi desenvolvida em uma escola de Educação Infantil da rede municipal de Pelotas, no Rio Grande do Sul, a partir da problemática: Que espaços e tempos são promovidos pelos professores de Educação Infantil para favorecer a ocorrência de experiências estéticas no cotidiano das crianças? Foi possível perceber que para a promoção de tempos e espaços que possibilitem experiências estéticas fazse necessário educar o olhar e a escuta docente. Este é um trabalho que começa desde a formação do professor de Educação Infantil e ocorre também no exercício de sua prática.
\end{abstract}

Palavras-chave: Arte; Educação Infantil; Experiências Estéticas; Formação Docente.

\section{AESTHETIC EXPERIENCES IN CHILDHOOD EDUCATION}

Abstract: This article deals with the research contributions: Aesthetic experiences in early childhood education - pedagocical practices designed by art. The research was carried out in an early childhood school in the municipal network of Pelotas, in Rio Grande do Sul, based on the problem: What spaces and times are promoted by early childhood teachers to favor the occurrence of aesthetic experiences in the daily lives of children? It was possible to perceive that in order to promote times and spaces that make aesthetic experiences possible, it is necessary to educate the teacher to look and listen. This is a job that begins with the formation of the teacher of early childhood education and also occurs in the exercise of their practice.

Keywords: Art; Child Education; Aesthetic Experiences; Teacher Formation.

\section{Das questões que deram forma à pesquisa}

A escolha pelo tema de pesquisa e pela problemática que ele aborda é sempre permeada por algumas questões, a inicial foi: É possível promover experiências estéticas para as crianças?

A experiência seja ela estética, ou não, sempre se refere a um modo muito particular de reação. Por isso, podemos pensar ações e estratégias que busquem promover experiências estéticas, através da configuração de tempos e espaços pensados para o fim de despertar a pausa em olhares apressados, a escuta sensível de vários sons, o movimentar dos corpos para exprimir o que vivenciam... No entanto, cada experiência é única. 
Mesmo sendo singular a cada indivíduo, a experiência estética, é uma experiência sensível e especialmente notável nas crianças. Por isso, o professor pode pensar o seu planejamento e observar como as crianças se sentem com suas propostas. São propostas que despertam experiências estéticas?

Todas estas questões permearam a condução da dissertação intitulada: Experiências estéticas na Educação Infantil - Práticas pedagógicas desenhadas pela arte. Que buscava responder essencialmente: Que espaços e tempos são promovidos pelos professores de Educação Infantil para favorecer a ocorrência de experiências estéticas no cotidiano das crianças?

Para contemplar o estudo sobre esta questão, a pesquisa acompanhou uma escola de Educação Infantil do município de Pelotas, no Rio Grande do Sul, que é tida como referência por apresentar uma proposta e um trabalho que inclui as artes em seu cotidiano.

Duas professoras participaram da pesquisa. Elas atuavam na docência do pré 1 e pré 2 , autorizaram visitas para observação e concederam entrevistas.

É importante destacar que as professoras fazem parte de uma instituição que dá destaque à arte, no entanto, elas não atuam com a disciplina de Arte, são professoras titulares da turma, no caso, professoras licenciadas em Pedagogia.

A escolha por este perfil de docentes ocorreu por compreender que o professor de Educação Infantil, graduado em Pedagogia, vivencia espaços e tempos nos quais as artes e as experiências estéticas se fazem presente. É relevante refletir: os conhecimentos sobre as interações com a arte e a promoção de experiências estéticas fizeram parte do currículo de formação inicial das professoras de Educação Infantil? E ainda, fazem parte da formação continuada?

As professoras que atuam em uma instituição que privilegia a arte conseguem promover espaços e tempos que privilegiam a proposição de experiências estéticas?

\section{Experiências estéticas}

Os estudos sobre experiências estéticas vêm se ampliando nos últimos anos, entretanto a estética compreendida como o estudo do belo, já é objeto de estudo para os filósofos desde a antiguidade. 


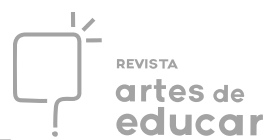

Inicialmente Platão e Aristóteles buscavam compreender o belo. Enquanto Platão acreditava que a arte afastava da verdade e nada mais era que uma cópia imperfeita do mundo, Aristóteles defendia que a realidade se dá por meio dos sentidos, Kant via o belo como algo subjetivo. Hegel dizia que o belo mudava conforme o tempo. Adorno destacou o poder subversivo da arte, destacando sua denúncia à lógica dominante do totalitarismo. Baumgarten assim definiu a estética: Ciência do conhecimento sensível.

A partir do entendimento de que a estética se ocupa do conhecimento sensível, aponto a contribuição de Herman sobre experiência estética: "A experiência estética, enquanto um modo de conhecer pela sensibilidade, em que se refugiam a pluralidade e a diferença, passa a se constituir uma via de acesso para a vida ética" (HERMANN, 2002, p. 11).

Por ser um modo de conhecer através da sensibilidade a experiência estética se relaciona com a capacidade de sentir. Está relacionada à reação a algo novo, à sensação que algo dado traz, e que, modifica o estado anterior à sua chegada. A experiência estética corresponde a uma reação sensível frente a uma experiência, que pode estar ou não vinculada às artes.

É uma experiência que altera o estado de estagnação do corpo e do espírito, proporcionando um conhecimento sensível. Por isso, nem toda experiência estética será relacionada às artes, mas implicará um modo de sentir marcado por ações como a contemplação, a criação, a observação reflexiva.

Duarte Jr. (2012, p. 363), destaca a importância de uma educação sensível e evidencia que "nosso encontro corporal, sensivel com o mundo, é também estético". Se referindo ao educando, diz que

Mais do que nunca, é preciso possibilitar ao educando a descoberta de cores, formas, sabores, texturas, odores, etc. diversos daqueles que a vida moderna lhe proporciona. Ou, com mais propriedade, é preciso educar o seu olhar, a sua audição, seu tato, paladar e olfato para perceberem de modo acurado a realidade em volta e aquelas outras não acessíveis em seu cotidiano. (DUARTE JÚNIOR, 2000, p. 29).

É preciso privilegiar a experimentação de materiais, experiências que privilegiem o sentir e não puramente o ensino de técnicas e de modos de fazer. É necessário educar o olhar para o contato com as obras de arte, mas também para a apreciação das paisagens.

Paulo Freire já apontava que ensinar exige estética e ética, decência e boniteza. " [...] $E$ ' por isso que transformar a experiência educativa em puro treinamento técnico é amesquinhar 


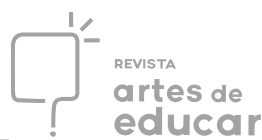

o que há de fundamentalmente humano no exercício educativo: o seu caráter formador" (FREIRE, 2007, p. 33).

Ao encontro de propostas que contemplem estética e ética, decência e boniteza, percebo as contribuições de Ostetto que destaca "é essencial o enriquecimento de experiências, promovendo encontros com diferentes linguagens, alimentando a imaginação para que meninos e meninas possam aventurar-se a ir além do habitual, à procura da própria voz, da sua poesia." (2011, p. 5). Por isso, no exercício da docência cabe a reflexão constante: Como proporciono experiências enriquecedoras para que as crianças possam se desenvolver em diferentes linguagens?

Nos espaços e tempos da Educação Infantil é possível pensar experiências que busquem promover a sensibilidade, a criatividade, um contato sensível com o mundo.

\section{Espaços e tempos como possibilidades de experiências estéticas}

Compreender a proposta de uma docência que prima por experiências estéticas vai além de pensarmos em possíveis atividades. O espaço deve se configurar como um ambiente sensível ao protagonismo das crianças, permitindo-lhes movimento, criação, instigando contemplação.

Tanto os espaços, quanto os tempos, informam concepções dos professores e também intenções. Segundo Ostetto, (2017) "até o espaço físico informa a perspectiva estética: suas paredes falam - às vezes denunciam... o descaso, a mesmice, o consumismo” (p. 59). A decoração, por exemplo, não se resume em simples enfeites de parede, ela direciona sentidos, mobiliza discursos e constitui-se como um elemento de educação estética.

O espaço, considerado também como ambiente, educa. Para esta afirmação o estudo e a apreciação de Reggio Emilia são fundamentais. Segundo Gandini (2016, p. 148), "O ambiente é considerado "terceiro educador", juntamente com a equipe de dois professores".

Gandini cita Malaguzzi, ao afirmar a importância do espaço na constituição de interrelações.

Valorizamos o espaço devido a seu poder de organizar, de promover relacionamentos agradáveis entre pessoas de diferentes idades, de criar um ambiente atraente, de oferecer mudanças, de promover escolhas e atividade, e a seu potencial para iniciar toda a espécie de aprendizagem social, afetiva e cognitiva. Tudo isso contribui para uma sensação de bem-estar e segurança nas crianças. Também pensamos que o espaço deve ser uma espécie de 
aquário que espelhe as ideias, os valores, as atitudes e a cultura das pessoas que vivem nele. (MALAGUZZI, apud GANDINI, 2016, p. 148)

Com isso notamos que o espaço é lugar passível de mudanças, que imprime significados, e é determinante percebê-lo desta forma, para reconhecer possibilidades e utilizálo como promoção de diferentes aprendizagens.

Vea Vecchi ao relatar uma experiência em que as crianças exploram um espaço que seria futura sede do Centro Internacional Loris Malaguzzi diz que as crianças comentam ao observar as colunas: "Bonitas estas colunas, mas são iguais demais, cada coluna é uma”. Nisso emerge "o forte desejo de reconhecer e dar importância à individualidade dentro da coletividade” (VECCHI, 2017, p. 77). A autora apresenta os passos das crianças na criação de protótipos para o que as crianças chamaram de "roupas" das colunas e destaca que os problemas enfrentados levaram ao aperfeiçoamento de técnicas o que é diferente da transmissão direta de uma habilidade técnica. Quando as crianças ganham a oportunidade de perceberem problemas e buscam resolvê-los, a criatividade ganha espaço.

Por isto, também se justifica o atelier nas escolas de Reggio Emilia. Este é um espaço onde a exploração tem lugar garantido assim como a individualidade dentro da coletividade também é respeitada. Gandini cita Malaguzzi que evidencia:

O atelier, em nossa abordagem, é um espaço adicional dentro da escola, onde é possível explorar com nossas mãos e nossas mentes, onde podemos refinar nossa visão através da prática das artes visuais, trabalhar em projetos ligados a atividades planejadas em sala de aula, explorar e combinar ferramentas, técnicas e materiais novos com outros bem conhecidos. (MALAGUZZI apud GANDINI, 2016, p. 143)

É importante destacar o que Loris Malaguzzi disse: "é possível explorar com nossas mãos e nossas mentes" aqui ele inclui crianças e professores numa tarefa que vai além de uma exploração tátil, manual, inclui também os processos mentais, a mente das pessoas que se relacionam no espaço do atelier, criando canais para uso da imaginação, criação, resolução de problemas. Com isso, percebe-se uma relação entre espaços e tempos, espaços que se configuram pela ação nos tempos. Ação que privilegia um tempo para criar, contemplar, se expressar. 


\section{A pesquisa em campo}

A escola na qual a pesquisa foi realizada tem uma proposta que contempla a arte em seu cotidiano. Foi possível perceber que essa proposta traz experiências significativas tanto para as crianças, quanto professores e toda a comunidade escolar.

Peixoto (2017, p. 37) diz que a escola fez parte do Movimento escolinhas de Arte no Brasil, e que, onde hoje fica a Escola Municipal de Educação Infantil Ruth Blank havia um prédio específico para uma Escolinha Municipal de Arte.

Quanto à proposta da escola, a autora comenta que

A escola atual possui uma proposta diferente daquela de 1963-1998, mas procurou manter o nome da primeira diretora, profissionais formados em arte e as Linguagens que eram trabalhadas na época da Escolinha de Arte (PEIXOTO, 2017, p. 37).

Até os dias atuais a escola é reconhecida pela comunidade pelotense como uma escolinha que privilegia as artes. Por este motivo considerei que os professores seriam sujeitos interessantes para esta pesquisa.

Foram realizadas seis observações em um período que compreendeu cerca de um mês e meio em cada turma. Uma das turmas de pré 1, com crianças de quatro anos de idade e outra de pré 2, com crianças de cinco anos.

Objetivando este contato próximo com a realidade observada, notei como eram encaminhadas as propostas que contemplavam as artes na Educação Infantil, quais os espaços e tempos disponibilizados para a ocorrência de experiências estéticas.

Foram realizadas observações do tipo sistemática/não participante, também conhecida como passiva, Gerhardt e Silveira (2009, p. 74) destacam que "esse tipo de observação é usado em pesquisas que requerem uma descrição mais detalhada e precisa dos fenômenos ou em testes de hipóteses". Não ocorriam propostas sugeridas por mim, mesmo assim as crianças partilhavam comigo as situações que viviam, faziam questionamentos e comentavam aspectos do cotidiano.

Durante as observações fiz uso de instrumentos para registro fotográfico e de vídeo e utilizei um diário de campo. Estes permitiram o registro de aspectos da realidade observada no momento em que ocorriam e permitiam a reflexão posterior.

Revista Interinstitucional Artes de Educar. Rio de Janeiro, V. 7, N. 1 - pág. 24-44 janeiro-abril de 2021: "Pedagogias Vitais: Corpo, Desejo e Educação" DOI: 10.12957/riae.2021.55372 
O diário de campo enquanto diário de bordo permite a escrita em tempo real, organizada cronologicamente com aspectos do que se vê, ouve e vivencia, permitindo uma análise reflexiva a partir do que foi registrado. Nas análises posteriores voltam à memória situações vivenciadas e a vivência prática dialoga com os estudos teóricos.

Como dito anteriormente, duas turmas foram acompanhadas. As professoras Rubi e Esmeralda participaram como sujeitos desta pesquisa. $\mathrm{O}$ quadro a seguir mostra o perfil das professoras.

Quadro 1: perfil das professoras

\begin{tabular}{|c|c|c|c|}
\hline Nome & Idade & Formação & Tempo de experiência \\
\hline Esmeralda & 45 & Magistério e Pedagogia & 27 anos na docência \\
\hline Rubi & 32 & Pedagogia & 6 anos na docência \\
\hline
\end{tabular}

Os nomes das professoras são fictícios, a fim de preservar a identidade das profissionais. A escolha por estes nomes decorre de uma experiência que vivi com as crianças em um dia de observação. Elas compartilharam comigo a busca por pedras preciosas, conversamos por um tempo sobre a qualidade das pedrinhas que eram encontradas no pátio da escola, o entendimento sobre a preciosidade ou não das pedras era diverso, referia-se a tamanho, brilho... Por isso, na escolha dos nomes das professoras criei uma analogia: as professoras são como pedras preciosas, pois possuem um potencial riquíssimo para encantar e um alto valor que embora não seja quantificado por um alto valor de mercado, gera uma riqueza de experiências que pode tornar sensível e bela a vida das crianças.

Oliveira (2012, p. 278) aponta que:

Na sua interação com as crianças, o professor pode ter como balizas dois movimentos: o de desvelar e o de ampliar. Ações que em conjunto podem transformar as crianças e a si próprio como o professor, sujeito sensível, envolvido no processo de criação das crianças e criador de sua prática docente.

Nos momentos de fruição de arte propostos pela escola foi possível perceber o envolvimento das profissionais com a proposta da instituição. $\mathrm{O}$ engajamento das professoras e demais integrantes da comunidade escolar demonstrou que existe um movimento da escola determinado a desvelar e ampliar as potencialidades das crianças por meio das artes, pensando estratégias, ações e experiências.

Revista Interinstitucional Artes de Educar. Rio de Janeiro, V. 7, N. 1 - pág. 24-44 janeiro-abril de 2021: "Pedagogias Vitais: Corpo, Desejo e Educação" DOI: 10.12957/riae.2021.55372 
Estar atenta a propostas que possam favorecer experiências estéticas implica conhecer um pouco as crianças, identificando quando há euforia, encantamento, quando o olho vibra, quando a voz quer comunicar algo. Foi isso que procurei fazer, observar não somente as propostas lançadas, como também a resposta das crianças frente ao que era proposto, para perceber o que tocava de forma especial, o que trazia uma qualidade de tempo e entrega permeada por uma experiência estética.

A seguir adentro nas categorias: Arte mais que um recurso interessante, Formação para lançar olhares e escutas sensíveis, Planejamento flexível que permita o encantamento com o que ocorre no meio tempo e Tempos e espaços para deslumbramentos. Estas categorias permitem apontar aspectos necessários para a criação de tempos e espaços na Educação Infantil que possibilitem a ocorrência de experiências estéticas.

É necessário compreender que a arte precisa ser vista com o valor que há nela mesma, e não somente como um recurso interessante. A formação docente necessita falar sobre estética, arte, deve criar meios para educar o olhar, as escutas dos futuros professores. O planejamento precisa ser flexível e atento às experiências que vivem as crianças. Os tempos e espaços precisam provocar deslumbramentos (encantamento, admiração).

\section{Arte mais que um recurso interessante}

Já é habitual que a arte pode ser um recurso rico e interessante para a prática pedagógica. No entanto, o que é pouco destacado é que ela tem valor nela mesmo, que é uma área do conhecimento que possui características próprias e que precisam ser compreendidas pelos educadores para que possamos buscar uma prática mais sensível e voltada para uma educação estética.

Vygotsky (2010, p. 352) destaca:

Aqui reside a chave para a tarefa mais importante da educação estética: introduzir a educação estética na própria vida. A arte transfigura a realidade não só nas construções da fantasia mas também na elaboração real dos objetos e situações. A casa e o vestiário, a conversa e a leitura, e a maneira de andar, tudo isso pode servir igualmente como o mais nobre material para a elaboração estética. 
Dito isto, percebemos que o sensível perpassa nosso modo de se relacionar com o mundo. Vygotsky (2010) ainda diz que: "De coisa rara e fútil a beleza deve transformar-se em uma exigência do cotidiano. O esforço artístico deve impregnar cada movimento, cada palavra, cada sorriso da criança." (p. 352), porque é a poesia de "cada instante" que constitui quase que a tarefa mais importante da educação estética. No entanto, ele destaca que é um sério perigo o artificialismo introduzido na vida, a "falsa beleza", pois: "O que deve servir de regra não é o adornamento da vida, mas a elaboração criadora da realidade, dos objetos e seus próprios movimentos, que aclara e promove as vivências cotidianas ao nível de vivências criadoras" (p. 352).

Sendo assim, por mais que a arte seja um recurso interessante, considero de importância extremamente significativa destacar sua potencialidade para a educação estética, para um modo mais sensível de se relacionar com as pessoas e coisas ao seu redor, elementos da natureza e criações humanas.

Durante as entrevistas as professoras foram questionadas nas formas como utilizavam as artes e relataram algumas situações. $\mathrm{Na}$ fala a seguir a professora apresenta como trabalhou a coordenação motora fina a partir das artes. Ela exemplificou a abordagem com as crianças:

\begin{abstract}
Nós agora vamos fazer o seguinte: o movimento da rena quando ela sobe e ela desce, (com a cor vermelha eles brincam com o pincel). Agora a rena vai caminhar retinho e ela vai subir e ela vai descer, (fomos trabalhar aquelas linhas). Agora a gente vai trabalhar o pozinho mágico, o pozinho mágico não é o mesmo caminhar da rena! Que cor que é essa aqui? Laranja. (Por quê? Porque eu procuro ver o que a Isabel tá trabalhando em Artes que são as cores secundárias, e eu procuro ver o que a Raquel trabalha em música para eu fechar, então estou sempre procurando o quê? Complementar as artes, então pra mim a linguagem da arte não é nenhuma dificuldade, ela é o meu recurso). (PROFESSORA ESMERALDA, 29/11/2018)
\end{abstract}

A professora contextualizou a proposta através de uma linguagem lúdica, apresentou as cores através de uma narrativa que buscava atrair a atenção das crianças. Entretanto, é importante salientar que as artes representam mais que cores e formas e que nem sempre ela servirá a uma utilidade que deixa vestígios no plano material.

Quando questionada se as artes trariam algum diferencial na educação das crianças, a professora Rubi respondeu:

Acredito que sim, porque a gente quer tanto trabalhar a alfabetização, fica tanto no letramento, mais eu acho que dá pra trabalhar dentro da proposta de artes, o letramento e a alfabetização, vai depender do que tu vai trazer né? É a faixa etária do lúdico, do brincar, do aprender através da alegria! E acho que Revista Interinstitucional Artes de Educar. Rio de Janeiro, V. 7, N. 1 - pág. 24-44 janeiro-abril de 2021: "Pedagogias Vitais: Corpo, Desejo e Educação" DOI: 10.12957/riae.2021.55372 
é possível aprender através da arte, acredito até que a arte me dá possibilidade de avaliar o nível de desenvolvimento deles, a questão cognitiva, a questão sentimental, eles deixam o registrinho deles ali, a capacidade de produção deles. (PROFESSORA RUBI, 29/11/2018)

Nessa fala a professora coloca que a arte é um instrumento de produção das crianças, que percebe que elas imprimem questões cognitivas e sentimentais. Também é possível compreender que para a professora a arte também é um recurso ao letramento e a alfabetização.

Quanto à intencionalidade relativa à utilização da arte na prática pedagógica a professora Esmeralda salienta que: "Eu dou tinta, mais o meu recurso é pedagógico, a minha visão é tecnicista, ela é tecnicista, mesmo que eu goste do Van Gogh, alguma coisa assim, eu não tenho este conhecimento, eu não tenho!" (PROFESSORA ESMERALDA, 29/11/2018). Com isto, a professora destacava que lhe falta conhecimentos e habilidades específicos das artes, e que costumeiramente ela utiliza a arte como um recurso, ou como técnica.

Esta professora atua em uma escola que vive as artes em seu cotidiano, e se inscreve numa postura de busca por conhecimento, de formação constante, mesmo assim, ainda percebe que a arte é um recurso, que demanda técnica.

A arte não se restringe a um recurso pedagógico, vista unicamente como um meio para se trabalhar outro conteúdo, ela tende a ser reduzida a um mero instrumento que torna a aquisição de um conhecimento mais prazeroso. Ela precisa ser reconhecida em sua potencialidade, que é a de uma formação estética.

A arte por ela mesma, o que propõe? Como lançar mão da música sem que ela sirva unicamente como oração antes do lanche, como ordenação para a fila ou estratégia para atingir o silêncio? Como um desenho pode representar mais que a ilustração de um personagem?

É necessário que o professor se inscreva em processos que lhes permita viver experiências sensíveis e diversas. De desenho, de pintura, de canto, de dança, de dramatização.... As artes não servem como meros acessórios, portanto, é necessário ter clara a intenção que se pretende com determinado uso de uma manifestação artística. Barbieri (2012, p. 146) ressalta que, “[...] Talvez, observar os quadros seja tão importante como observar uma jabuticabeira em flor, ou observar o caminho das formigas”. Dito isto, percebe-se que o compromisso está no desenvolvimento da formação estética, que prevê o exercício da sensibilidade. 
A arte não é um recurso, a arte está a serviço de uma formação estética, que educa o olhar, as escutas, o movimentar dos corpos tanto para as linguagens artísticas quanto para o agir no mundo.

É preciso que as crianças reconheçam este potencial sensível que a arte nos permite vivenciar, dito isto, as práticas pedagógicas pensadas pelos professores precisam partir da premissa de que os espaços e tempos devem possibilitar criação, olhares e escutas sensíveis, uma educação que prima pelo sensível, pela formação estética.

\title{
Formação para lançar olhares e escutas sensíveis
}

Um dos fatores que dificultam a utilização da arte para além de um recurso interessante reside na formação de professores. É desafiador para muitos profissionais verem as artes com uma finalidade diferente a do recurso. Nogueira aponta que em sua pesquisa "ficou claro que o grande entrave ainda reside na formação, inicial e continuada, das educadoras infantis" (NOGUEIRA, 2005, p. 10).

Durante as entrevistas as professoras comentaram alguns aspectos referentes à formação:

\begin{abstract}
eu vô te dizer assim: que a arte eu chamo de terceiro olho tá? Porque tu vai dá pra eles um jogo e aquele jogo sai tantas coisas lá da vidinhas deles que tu começa justificar porque que ele é assim, então eu acho que pra ti trabalhar uma temática, alguma coisa mais específica que lida com sentimentos, tem que ser um profissional que vai saber conduzir, como vai trabalhar com isso? Eu adoro harmonização, tentei esse ano de tarde, eu dei três harmonizações. Fui ali coloquei uma musiquinha calma, trabalhei de tocar no colega, fiz isso porque a colega estava comigo, não me sinto habilitada a fazer hoje, porque hoje não é o dia certo, hoje estão a mil, não fecha. Aí eu acho assim, lidar com coisas específicas da arte envolve sentimento? Envolve. Envolve emoção? Envolve. Envolve criatividade? Envolve. Mas tem que ser um especialista, porque se pega uma pessoa leiga, ela pode deixar uma criança ridicularizada para o resto da vida, ou ela pode imaginar mil coisas e levar a criança, expor a criança, ao ridículo. (PROFESSORA ESMERALDA, 29/11/2018)
\end{abstract}

A professora falava sobre a relação das crianças com propostas que envolvem a criação, os sentidos. Ela citou uma experiência envolvendo a música, que costumava desenvolver com as crianças. Comentou que é necessário estar atento ao contexto para perceber se a atividade servirá ao propósito, da importância de sentir o "timing" do grupo, mas enfatiza que para lidar 
com os sentimentos, com a emoção, a criatividade, precisa-se passar por uma formação para este fim, do ponto de vista da professora "tem que ser um especialista".

O especialista ao qual a professora se refere, trata-se do profissional de artes, de música, do teatro, da dança. Para a professora as habilidades pertinentes às artes são desenvolvidas por profissionais especializados para este fim, que passaram por uma formação acadêmica.

De acordo com Perissé (2014, p. 41-42), a formação estética contribui para a vida intelectual e profissional do professor. "Formar-se é entrar em contato com valores de toda ordem. Especificamente, o contato com valores estéticos (e também com informações, dados, terminologias estéticas... deve ser ocasião para vislumbrarmos projetos de vida humanizadores". O autor destaca que é no contato de cada um com a arte, com uma obra, que se estabelece um encontro humano e humanizador, que se percebe aquilo que um artista sentiu, que se habita com ele na obra de arte. Com isso, percebo que é importante destacar que cabe ao professor estabelecer esse mesmo tipo de encontro com as crianças, suas produções e expressões, por isso a formação estética no decorrer da formação acadêmica e na formação continuada dos professores é tão importante.

Quanto à formação dentro do curso de Pedagogia ou curso por iniciativa própria, a professora Rubi disse:

Não, nunca tive e foi tipo... uma cobrança do meu eu, será que eu vou conseguir? Será que... né... e quando cheguei aqui... não é fácil, tem que fazer eles produzirem, produzirem, produzirem, mais no fim eu fui vendo que não é o tanto quanto me falaram e acho que, como tinha te dito lá, eu me encontrei, até gostei, gosto desse método, dessa metodologia de ensino deles aqui. (PROFESSORA RUBI, 29/11/2018)

Neste momento da entrevista ela falou dos desafios ao ingressar numa escola com uma proposta de ensino voltada as artes. Inicialmente, trabalhar numa escola assim, lhe trouxe certa preocupação, representou um desafio, visto que nunca havia tido aproximação tão frequente com as artes.

Ambas as professoras destacaram que no curso de Pedagogia viram muito pouco sobre as artes.

Não, não. Eu sempre procurei fora, porque eu fazia oficinas de arte, há muitos anos atrás existia oficinas de aquarela, oficina de artes, oficina de tradição do Rio Grande do Sul, isso dai na década de 80 que eu tô falando, então a gente tinha. (PROFESSORA ESMERALDA, 29/11/2018) 


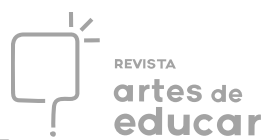

Quanto à presença da Arte nos cursos de Pedagogia, Ostetto e Silva (2018, p. 194) citam Martins e Lombardi que apontam que o nosso país apresenta uma ínfima inserção da arte nos currículos, quando não inexistente.

Vecchi (2017, p. 70) aponta que, mesmo em casos onde os professores recebem formação artística, muitos ainda têm dificuldade de "enlaçar escutas sensíveis com as crianças e o entorno", por isso trata-se de um exercício constante de sensibilidade para com o meio e as crianças. É preciso tornar o trabalho de educação estética parte integrante da formação dos professores e sendo assim, empenhar esforços para que seja uma característica da identidade docente.

Ao falar da formação de professores Vecchi (2017, p. 70) destaca: "não está compreendida uma preparação sensível à estética e que a considere um elemento potente de compreensão e conexão com a realidade, formadora de cultura sob um aspecto mais amplo”. Mesmo em casos onde os professores recebem formação artística, muitos ainda têm dificuldade de "enlaçar escutas sensíveis com as crianças e o entorno", por isso trata-se de um exercício constante da sensibilidade para com o meio e as crianças. É preciso tornar o trabalho de educação estética parte integrante da formação dos professores e sendo assim, empenhar esforços para que seja uma característica da identidade docente.

Destaco também, a importância da atitude do professor que se insere em um movimento de busca, que acredita em um trabalho que privilegia as artes. Mesmo apontando limitações na formação, ambas as professoras entrevistadas demonstraram que buscam compreender o papel da arte no cotidiano das crianças, participam com disposição dos momentos culturais e artísticos que a escola vivencia e refletem sobre suas ações.

\section{Planejamento flexível que permita o encantamento com o que acontece no meio tempo}

Quando o planejamento é traçado a longo prazo e tem em vista linguagens e experiências diversas, ele possibilita que um dia de sol seja um bom dia para aquele passeio ao redor da escola, que a chuva que cai crie um bom ambiente para a contação de uma história, para assistir um filme,...

É possível adequar o planejamento as mais variadas linguagens e experiências. Para isso é importante que o professor se encante com as situações. Um olhar sensível do professor traça um planejamento flexível e que se encanta com situações que acontecem no meio tempo, aquele 
que ocorre entre uma e outra atividade planejada. As brincadeiras livres com os brinquedos, com a massinha de modelar, com materiais diversos, trazem narrativas e experiências não previstas que nos mostram formas de interação das crianças, o potencial criativo que possuem e a habilidade para fazer de um momento livre um momento de infinitas possibilidades. Nós adultos aprisionamos o tempo, as crianças o tornam livre, para uma brincadeira, para um jogo, para criar.

A natureza, por exemplo, apresenta um universo de situações que podem ser observadas, investigadas, vivenciadas. A textura das folhas, o barulho da água, a cor da terra, o formato das pedras, os animais em seus diferentes tamanhos e características, a estrutura das árvores. Barbieri destaca que "Temos que escolher e preparar oportunidades maravilhosas para as crianças, porque elas merecem vivê-las e levarão tais experiências consigo" (BARBIERI, 2012, p. 116), a autora ainda destaca que conhecer diferentes ambientes in loco é de extrema importância e defende que alunos e professores passem por essa vivência.

Trago a seguir uma escrita de meu diário de campo:

Num dos encontros de observação a professora auxiliar convidou as crianças para darem um passeio fora da sala e observarem a natureza ao redor da escola, agora as crianças desenham sobre o que viram. Dois meninos trouxeram consigo algumas folhinhas, cuidam com muita atenção porque parece frágil e mostram para os colegas. É marcante como cada um focou sua atenção num aspecto, a roda gigante, as pessoas passeando, mesmo as crianças que estão na fase das garatujas contam histórias sobre seus desenhos (Pré 1, Diário de campo, 30/10/2018, 16h10). 


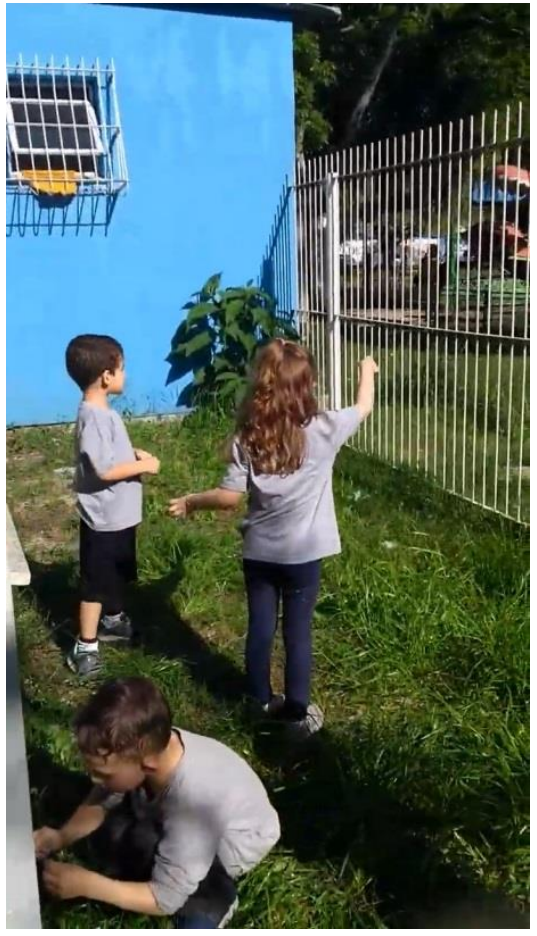

Figura 1: Crianças observando a escola e redondezas.

Fonte: Registro fotográfico da pesquisadora, 2018.

A proposta de observação ativa, a partir do passeio, aguçou o olhar das crianças ao entorno. Motivou a repararem no que lhes chamava a atenção, enquanto alguns trouxeraram folhinhas, florzinhas, outros trouxeraram apenas as memórias para registrar no papel.

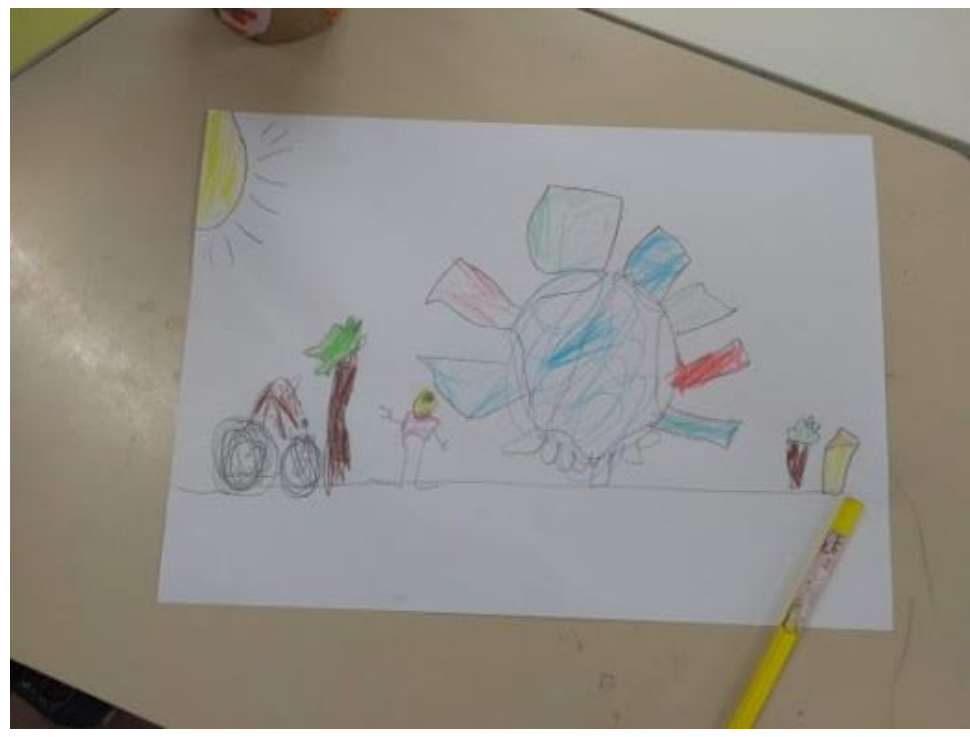

Figura 2: Desenho da roda gigante que fica na praça ao lado da escola.

Fonte: Registro fotográfico da pesquisadora, 2018. 


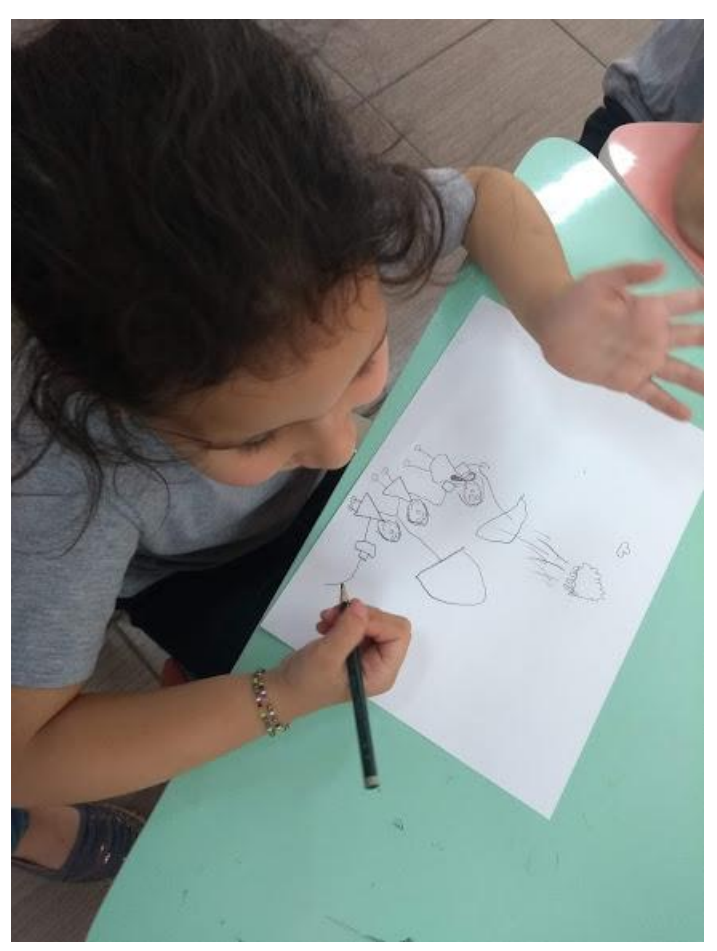

Figura 3: Desenho das pessoas passeando pela praça.

Fonte: Registro fotográfico da pesquisadora, 2018.

Através dos desenhos das crianças pode-se percber que a atenção de cada uma das crianças se volta a um aspecto que lhes toca de forma particular. Cabe destacar o papel da professora ao direcionar o olhar, instigando a observação.

Enquanto passeavam as crianças eram convidadas a olhar a escola, ao redor da mesma, podiam observar se haviam plantas, pessoas, o que as pessoas faziam.

Segundo Barbieri (2012) o desenho de observação não é uma reprodução do que está sendo observado, ele torna visível o que aos olhos da criança é selecionado como importante.

[...] O exercício do desenho de observação possibilita que cada criança mostre como vê os elementos e as relações entre eles, como interpreta singularmente o que é observado. Ao educador, cabe inventar a possibilidade para que isso aconteça, ou observar na situação que está sendo vivida, uma necessidade que brota do interesse da criança por determinado objeto. Se ela está interessada em ver um pião rodando, por que não desenhar o movimento do pião? Como educadores, precisamos estar atentos ao que vai enriquecer o universo das crianças. (BARBIERI, 2012, p. 101)

O processo de construção de um desenho de observação implica na seleção dos elementos sensíveis, pois no momento do desenho, a criança vivencia a elaboração do que está sentindo, do que aprecia e ainda adquire o poder de sintetizar na forma de um objeto o que desperta seu interesse e lhe chama a atenção. É uma prática que conecta o olhar ao sensível. Revista Interinstitucional Artes de Educar. Rio de Janeiro, V. 7, N. 1 - pág. 24-44 janeiro-abril de 2021: "Pedagogias Vitais: Corpo, Desejo e Educação" DOI: 10.12957/riae.2021.55372 
As situações inesperadas, não previstas no planejamento, também desencadeiam importantes processos perceptivos que merecem a atenção do professor, o aprofundamento do olhar e o exercício da sensibilidade. Por isso é tão importante que o planejamento seja flexível e permita o encantamento com o que acontece no meio tempo.

\section{Tempos e espaços para deslumbramentos}

Foi possível perceber que na maior parte das vezes os tempos e espaços costumam ser pensados para atender a uma necessidade do professor, geralmente associada a aprimorar alguma competência cognitiva ou motora.

Mas é possível pensar o espaço da sala e de vários ambientes da escola, a fim de criar ambientes promotores de experiências, disponibilizando espaços para brincadeiras de faz de conta, para desenho, para dança, leitura...O tempo é pensado pelo professor que atento as experiências que ocorre nos espaços, dá prioridade a qualidade do tempo e não a quantidade de "trabalhinhos" que propõe.

Durante a entrevista, conversamos sobre a organização de tempos e espaços, perguntei para as professoras se elas acreditam que o professor pode organizar espaços diferenciados na sala, como percebem que os tempos devem ser conduzidos:

A professora Rubi comentou:

Eu acredito que sim. Ali mesmo que te falei da roda de conversa, cada um tem seu momento, pra dividir experiências, do eu, família, eu lá fora, eu como aluno aqui dentro. Penso no espaço da sala de aula sim, prá determinadas atividades, a hora do conto, a literatura, procuro levar eles prum cantinho mais aconchegante, sentar eles em círculo, perninhas de índio, vocês me olham, vocês me escutam, e eu leio, depois vocês tiram a dúvida, depois relatam, penso bastante também nas atividades físicas, quando não é possível ser realizado na rua, também penso, também organizo na sala, procuro encontrar espaços, apropriado pra tal atividade, inclusive eu fiz, um circuito, circuito não, gincana das cores, tinha planejado pra fazer na rua, mas o que que aconteceu, um vendaval, do nada, não parava nada no lugar, aí eu vim pra sala, abri espaço, deixei aconchegante, dum jeitinho que desse pra ser realizada tal proposta de atividade, então acho que penso, penso. Às vezes acontece de a gente não estar pronta, não ter pensado na hora de planejar, mas aí chega aqui e acontece toda essa organização né? (PROFESSORA RUBI, 29/11/2018)

Nota-se uma preocupação em organizar os espaços de forma que as crianças possam desenvolver o hábito de ouvir o outro, falar, também ocorre uma adaptação do espaço para a Revista Interinstitucional Artes de Educar. Rio de Janeiro, V. 7, N. 1 - pág. 24-44 janeiro-abril de 2021: "Pedagogias Vitais: Corpo, Desejo e Educação" DOI: 10.12957/riae.2021.55372 
realização das propostas pensadas pela docente, a preparação do espaço para momentos que peçam mais proximidade e aconchego, como por exemplo, os da roda de conversa.

Há muito que explorarmos no espaço da instituição! Uma roda de conversa com cadeiras, no tapete da sala, no pátio embaixo de uma árvore,... Há de se pensar possibilidades para um lanche com direito a piquenique na área externa da sala, um lanche especial onde a mesa é intencionalmente organizada com a ajuda das crianças,... Existe a possibilidade de pensarmos espaços na sala que permitam a criação de desenhos durante os momentos livres, espaço para uso de fantasias, máscaras,... em todas estas situações onde o espaço é privilegiado percebemos uma qualidade de tempo diferente da habitual. Quando organizamos o momento do lanche, de forma especial, seja nas mesas da sala, no refeitório, numa toalha para piquenique, ensinamos sobre atenção, cuidado, socialização.

Já a professora Esmeralda com relação à organização dos espaços disse que costuma trocar a disposição das mesas, vai adequando as necessidades das atividades que propõe:

[...] tu nunca tinha visto eles em dois ainda, por que em dois? Porque a gente já começou os jogos em dupla, é a torre, é o bingo, tá? E é os blocos lógicos. Então eu preciso que, em dupla em consigo ver quem consegue e quem não consegue, então agora eles tão em dupla, quando eles tão em coletivo, o quê que eu trabalho coletivo? É o desenho deles, que eles precisam de alguma atividade de registro, o recorte eles trabalham coletivo, a pintura é coletiva, mas tudo que eu quero ter cognitivo, é em dupla (PROFESSORA ESMERALDA, 29/11/2018).

Aqui a professora lança mão da organização do espaço para acompanhar o desenvolvimento cognitivo das crianças, uma estratégia que ela encontrou para acompanhar o desenvolvimento das crianças com relação às propostas lançadas.

Também é importante considerar que a organização do espaço pode promover a criação de cenários para as brincadeiras de faz de conta, que mesas podem se transformar em um túnel, caverna, casa, castelo, que as cadeiras podem representar personagens criados pela imaginação, tronos, bancos de praça, poltronas de ônibus.

Essa atenção para novos arranjos espaciais na sala permite a qualidade das experiências e do tempo que se vive nas instituições de educação infantil. Por isso, sempre que falo em tempo, falo mais da qualidade deste, do que da quantidade. Qualidade de tempo que é aprimorada pela promoção de espaços que permitam a ampliação de saberes sensíveis e de uma educação estética, que prevê a beleza nos aspectos do dia a dia. 


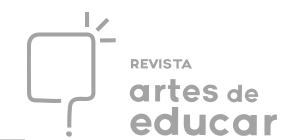

Por isso, também é importante falar da importância de um tempo livre na rotina das crianças, tempo intencionalmente planejado para ser utilizado pela criança para que ela faça uso brincando, pintando, desenhando, dançando, cantando,...

O tempo livre numa sociedade que vive sem tempo, é um privilégio e não pode ser negado a criança, oportuniza a liberdade de escolha, de expressão e é um importante meio para que o professor perceba o que é do interesse para a criança e como ela se expressa.

Estas habilidades possíveis de serem potencializadas às crianças implicam que o professor adote uma atitude de promoção de produção, que ele ofereça tempos e espaços onde as crianças possam ser livres para criar.

Ainda nos dias de hoje, há profissionais que acreditam que o professor que disponibiliza tempo livre, não sabe o que fazer com as crianças. Tempo livre para as crianças, não é tempo livre para o professor, que precisa exercer sua sensibilidade para ser aquele que também brinca, que propõe, que observa com olhos e ouvidos atentos, resguardando olhares e escutas sensíveis.

Além do mais, mesmo quando a atividade é orientada, o tempo deve privilegiar o ritmo das crianças, o tempo delas, permitir a interação que ocorre por meio do diálogo, da observação entre as crianças e suas produções.

Meira e Pilloto (2010) contribuem para a reflexão a respeito dos ritmos quando promovem a questão: "Como modular olhares apressados, controlar o ritmo das ações para que delas possam emergir potencialidades poéticas e estéticas?". Acrescento: Como pensar espaços e tempos que modulem olhares e escutas sensíveis, possibilidades de criação, atitudes de contemplação?!

\section{Considerações finais}

Aceder do latim accedere, ${ }^{\text {iii }}$ refere-se à ação de se aproximar. Exupéry fala que conhecer não consiste em demonstrar ou explicar, mas sim, trazer as coisas à visão, torná-las próximas. Esse trabalho recomenda proximidades, sensibilidade nas ações e a busca por tempos e espaços que privilegiem experiências estéticas.

Vivemos um tempo que carece "aceder" trazer as coisas à visão, torná-las e tomá-las próximas.

Nossa sociedade cada vez mais tem se distanciado de um saber sensível, das apreciações estéticas e vai à busca de status social, quantidade de mercadorias,... Deixando de apreciar o Revista Interinstitucional Artes de Educar. Rio de Janeiro, V. 7, N. 1 - pág. 24-44 janeiro-abril de 2021: "Pedagogias Vitais: Corpo, Desejo e Educação" DOI: 10.12957/riae.2021.55372 
cheiro da terra molhada, o barulho da chuva, o sol ao entardecer, o canto dos pássaros,... Reproduzem-se canções, quadros, danças,... de forma mecânica, por estarem "em alta" "na moda", não pelo valor sensível que manifestam em cada um de nós. Por tudo isso, percebe-se que é urgente e necessário falar de arte, sobretudo numa perspectiva estética e sensível.

Perceber para onde caminhamos e buscar evitar que a infância siga o mesmo ritmo é um compromisso que nós professores precisamos assumir. No entanto, tem sido um desafio para os professores criar essa conexão com o sensível por meio das artes, visto que, a formação tem sido deficitária no sentido de lançar estudos sobre a educação estética. Desta forma, muitos professores seguem usando a arte para fins de desenvolvimento motor, de construção moral, interesses alheios aos da arte. Visto que, para mim, o interesse da arte é com a vivência de sentimentos num plano que desenvolve o saber estético e sensível.

É necessário pensar tempos e espaços para além de finalidades referentes à acomodação das crianças na sala e a adequação de atividades à rotina, esse é um exercício que exige que nos encantemos com as brincadeiras das crianças, com as necessidades delas de se expressarem, interagirem, criarem. $\mathrm{O}$ tempo da criança nem sempre se encaixa ao pré-estabelecido pelos professores, os espaços ganham significados atribuídos pelas crianças e pode permitir experiências pensadas para muito além do que já foi planejado pelos professores.

Favoreceremos tempos e espaços possíveis de experiências estéticas à medida que educarmos o nosso olhar com a ampliação de nossos acervos culturais e artísticos, com a observação reflexiva às crianças e às nossas práticas. Não é uma tarefa que demanda o esforço exclusivo das políticas educacionais, nem que demanda esforço único dos professores, mas uma junção de esforços que vise uma melhoria das experiências vividas na escola, que preze pela beleza das experiências.

\section{REFERÊNCIAS}

BARBIERI, Stela. Interações: onde está a arte na infância? São Paulo: Blucher, 2012.

DUARTE JUNIOR, João Francisco. O sentido dos sentidos: a educação (do) sensível. 2000. 233 p. Tese (doutorado) - Universidade Estadual de Campinas, Faculdade de Educação, Campinas, SP. Disponível em: <http://repositorio.unicamp.br/bitstream/REPOSIP/253464/ 1/DuarteJunior_JoaoFrancisco_D.pdf>. Acesso em: 16 mar. 2018.

FREIRE, Paulo. Pedagogia da autonomia: saberes necessários à prática educativa. 35 . ed. São Paulo: Paz e Terra, 2007, 148 p.

GANDINI, Lella. Espaços educacionais e de envolvimento pessoal. In: EDWARDS, Carolyn. Revista Interinstitucional Artes de Educar. Rio de Janeiro, V. 7, N. 1 - pág. 24-44 janeiro-abril de 2021: "Pedagogias Vitais: Corpo, Desejo e Educação" DOI: 10.12957/riae.2021.55372 
GANDINI, Lella. FORMAN, George. As cem linguagens da criança: a abordagem de Reggio Emilia na educação da primeira infância. Porto Alegre: Penso, 2016. p. 137-149.

HERMANN, Nadja. Razão e Sensibilidade: Notas sobre a contribuição do estético para a ética. Revista Educação e Realidade. N. 27(1): p. 11-26, jan./jun. 2002.

OLIVEIRA, Zilma Ramos (org.). O trabalho do professor na Educação Infantil. São Paulo: Biruta, 2012.

OSTETTO, Luciana Esmeralda. Sobre a organização curricular na Educação Infantil: conversas com as professoras a partir das Diretrizes Curriculares Nacionais. Revista Zero-a-seis. v. 19, n. 35 p. 46 - 68 | jan-jun 2017. Disponível em: <https://periodicos.ufsc.br/index.php/zeroseis /article/view/1980-4512.2017v19n35p46/34163> Acesso em 11 mai 2018.

PEIXOTO, Marge Faria do Amaral. Escolinha Municipal de Arte de Pelotas: Memória, História e Ensino de Arte. 2017. 128 f. Dissertação (Mestrado em Artes Visuais) - Programa de Pós-Graduação em Artes Visuais, Universidade Federal de Pelotas, Pelotas. Disponível em: $<$ http://guaiaca.ufpel.edu.br:8080/bitstream/prefix/3913/1/Marge\%20Faria\%20do\%20Amaral \%20Peixoto_Disserta\%C3\%A7\%C3\%A3o.pdf>. Acesso em 15 jun 2019.

PERISSÉ, Gabriel. Estética e Educação. 2. Ed. Belo Horizonte: Autêntica Editora, 2014, 100 p.

VECCHI, Vea. Arte e criatividade em Reggio Emilia: explorando o papel e a potencialidade do ateliê na educação da primeira infância. São Paulo: Phorte, 2017.

VYGOTSKY, Lev. Semenovich. Psicologia Pedagógica. 3. ed. São Paulo: Editora WMF Martins Fontes, 2010, 561 p.

\footnotetext{
${ }^{\text {i }}$ Mestre em Educação pela Universidade Federal de Pelotas (UFPel), Professora de Rede Municipal de Pelotas e da Rede Estadual do Rio Grande do Sul. Brasil. ORCID https://orcid.org/0000-0002-5761-0024.

ii Doutora e Mestra em Educação (PPGE/FaE/UFPel). Professora Associada no Centro de Artes da Universidade Federal de Pelotas, RS, onde ministra disciplinas na área de Fundamentos da Educação em Artes Visuais. Docente no Programa de Pós-Graduação em Educação (PPGE/FaE/UFPel), Mestrado e Doutorado, na Linha de Pesquisa Formação de Professores: Ensino, Processos e Práticas Educativas. ORCID https://orcid.org/0000-0001-9600$\underline{1988}$

iii Dicionário Online de Português. Disponível em: https://www.dicio.com.br/aceder/. Acesso em: 15 jun. 2019.
} 